\title{
Development of Ecologically Acceptable Chlorpyrifos Formulation for Effective and Safe Application
}

\author{
Yasser El-Nahhal*, Bayan Wheidi, Said El-Kurdi \\ Department of Environment and Earth Science, Faculty of Science, The Islamic University—Gaza, Gaza, Palestine \\ Email: *y_el_nahhal@hotmail.com
}

How to cite this paper: El-Nahhal, Y., Wheidi, B. and El-Kurdi, S. (2016) Development of Ecologically Acceptable Chlorpyrifos Formulation for Effective and Safe Application. Journal of Encapsulation and Adsorption Sciences, 6, 91-108. http://dx.doi.org/10.4236/jeas.2016.63008

Received: August 19, 2016

Accepted: September 25, 2016

Published: September 29, 2016

Copyright $\odot 2016$ by authors and Scientific Research Publishing Inc. This work is licensed under the Creative Commons Attribution International License (CC BY 4.0). http://creativecommons.org/licenses/by/4.0/

\begin{abstract}
Application of the commercial formulation of chlorpyrifos has resulted in considerable environmental contamination. This study was designed to develop environmentally acceptable chlorpyrifos formulation for safe and effective application. This involved the modification of clay surfaces from hydrophilic to hydrophobic via ionexchange reaction with organic cations. The resulting organo-clay complexes were tested for adsorption and release of chlorpyrifos. HPLC and FTIR measurements showed considerable adsorption and strong interaction between chlorpyrifos molecules and the organo-clay complexes. Basal spacing results emphasized the formation of suitable micro-pores for chlorpyrifos molecules. HPLC and bioassay techniques confirmed the slow release of chlorpyrifos. Leaching potential showed retention of chlorpyrifos in the top soil. Therefore application of organoclay formulation of chlorpyrifos may reduce their potential environmental contamination and produce safe applications.
\end{abstract}

\section{Keywords}

Chlorpyrifos, Adsorption, Basal Spacing, Organo-Clay, Leaching Potential

\section{Introduction}

Chlorpyrifos is an organophosphate insecticide widely used in agricultural and public health sectors [1]. The application of the commercial formulations of chlorpyrifos created many environmental problems. For instance, residues of chlorpyrifos have been detected in fruit, vegetables, water and soil samples in many parts of the world [2]-[7], in outdoor air samples [8], in oceanic air samples [9], in Alaskan Arctic estuaries [10], in dust [11] and in carpets [12]. Furthermore, Chlorpyrifos has been shown to cause 
environmental health problems [13]-[15], ecological disturbance [16] and toxic effects to aquatic life [17]-[21]. Recent published work revealed human toxicity due to long term exposure to chlorpyrifos formulations [22]. Moreover, chlorpyrifos has been shown to: induce neurite retraction in differentiating neuronal cells, [23], cause cytotoxicity [24] and reduce growth, enzyme activity and chlorophyll A synthesis of fresh water microalgae [25]. The annual report revealed the application of large quantities of chlorpyrifos that reached to 18,125 Liter [26].

Moreover, application of commercially available formulations of chlorpyrifos may result in subsequent leaching, movement and migration from the top soil layer to deeper soil depths. This may also result in losing the insecticidal activity that has to be maintained in the tope soil layer where some soil insects are spending parts of their life cycle. Accordingly, the authors of this study initiated the idea of developing clay based formulation for environmentally safe and effective application of chlorpyrifos. The rationale of this study is emerged from the fact that modifying the hydrophilic surfaces of clay minerals to partially or totally hydrophobic through an ion exchange reaction using a suitable organic cation may enhance the adsorption of chlorpyrifos and consequently reduce its movement in soil and producing safe and effective application in the environment.

\section{Materials and Methods}

\subsection{Materials}

Bentonite clay was obtained from the Source Clays Repository, Clay Minerals Society, Columbia, MO, USA. Its cation exchange capacity is equal to $0.8 \mathrm{mmol} / \mathrm{g}$ [27]. Chlorpyrifos $99.9 \%$ purity was purchased from Sigma-Aldrich, Germany. The commercial emulsion formulation of chlorpyrifos (Dursban EC20) was purchased from a certified pesticide vendor in Gaza.

The organic cation compounds benzyltrimethyl ammonium (BTMA), benzyltriethyl ammonium (BTEA), benzyltributyl ammonium (BTBA) and phenyltrimethyl ammonium (PTMA) were purchased from Sigma-Aldrich, Germany and utilised without further purification. Their chemical structures are illustrated in Figure 1.

\subsection{Soil Collection}

Soil samples were collected from the top $20 \mathrm{~cm}$ of a multi-agricultural soil in Gaza which has no history of chlorpyrifos application Lewhadi Farm. The soil samples were air dried, sieved through $2 \mathrm{~mm}$ mesh and stored in plastic bags in the laboratory. The physicochemical properties of the soil ( $\mathrm{pH}$, electrical conductivity (EC), Calcium carbonate $\left(\mathrm{CaCO}_{3}\right)$ content, organic matter content (OM), organic carbon content (OC) and soil texture) were determined using standard methods.

\subsection{Preparation of Organo-Clay Complexes}

The following clay-BTMA 0.5/-PTMA 0.5/-BTEA 0.25 and clay-BTBA 0.8 complexes were prepared by ion exchange reaction using drop wise addition of the organic cation 


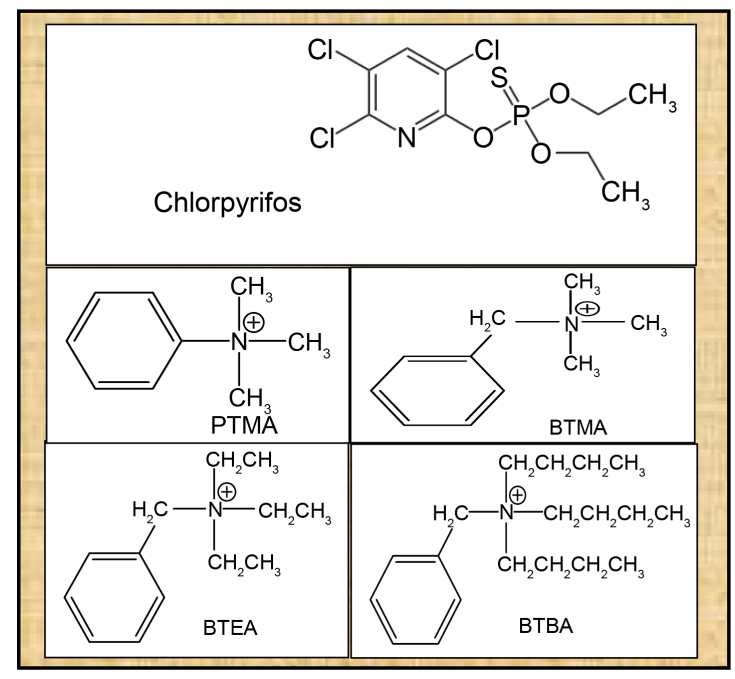

Figure 1. Chemical structure of the chemicals utilized.

to suspended clay (1\%) under continuous magnetic stirring for $48 \mathrm{~h}$ at room temperature [28] [29]. The yielded clay complexes were separated after $30 \mathrm{~min}$ centrifugation $(6000 \mathrm{~g})$, the precipitate was washed three times with distilled water up to have free chloride ion in the washing water, lyophilized and ground to $50 \mu \mathrm{m}$ and kept in plastic bottles at room temperature.

\subsection{Adsorption of Chlorpyrifos}

Adsorption of chlorpyrifos was performed at room temperature $\left(25^{\circ} \mathrm{C} \pm 1^{\circ} \mathrm{C}\right)$ at a fixed concentration of chlorpyrifos not too low and not too high $(200 \mu \mathrm{g} / \mathrm{g})$. In this procedure the required concentration of chlorpyrifos was prepared in $25 \mathrm{ml}$ distilled water and transferred to $30 \mathrm{ml}$ centrifuge tubes containing $10 \mathrm{mg}$ clay or organo-clay complexes. The tubes were kept overnight $(24 \mathrm{hr}$ ) for horizontal shaking at $140 \mathrm{rpm}$. The supernatants were then separated by centrifugation at $6000 \mathrm{~g}$ for $1 \mathrm{~h}$. The remaining concentrations of chlorpyrifos in the solutions were determined by HPLC as described below.

\subsection{Adsorption Isotherms}

Adsorption isotherm of chlorpyrifos on each organo-clay complex was performed in distilled water by making a series of dilutions ranging from $0.0-1 \mathrm{mg} / \mathrm{g}$ in a total volume of $25 \mathrm{ml}$. Then each volume was transferred to a $30 \mathrm{ml}$ centrifuge tube containing $10 \mathrm{mg}$ of clay or organo-clay complex. The tubes were sealed and kept under horizontal shaking for $48 \mathrm{~h}$ [30] then centrifuged at $6000 \mathrm{~g}$ for $1 \mathrm{~h}$ to separate the supernatants. The remaining concentrations of chlorpyrifos in the solutions were determined by HPLC as described below. The adsorbed amounts were calculated using Equation (1).

$$
Q_{s}=\left(Q_{i}-Q_{e}\right) V / M
$$

where $Q_{i}$ and $Q_{e}$ are the initial and equilibrium concentration $\mathrm{mg} / \mathrm{l}$, and $Q_{s}$ is the concentration in the solid phase $\mathrm{mg} / \mathrm{g}$ (the adsorbed amount). $V$ is the volume (L) and $M$ is 
the mass of adsorbent ( $\mathrm{g})$.

\subsection{HPLC Measurement}

As described previously [30], chlorpyrifos concentrations in the supernatants were determined by Chromtech HPLC with Diode Array Detector (DAD) equipped with manual-injection system. The column was $200 \mathrm{~mm} \times 4.6 \mathrm{~mm}$ (i.d.) reverse-phase. Packing ODS-BP $5 \mu \mathrm{m}$ (C18), injection volume was $50 \mu \mathrm{l}$ and wave length of detection was 280 $\mathrm{nm}$, mobile phase was water:methanol 10:90. The flow rate maintained $1.5 \mathrm{ml} \cdot \mathrm{min}^{-1}$ and retention time $8 \mathrm{~min}$. External calibration and standard curve measurements were done before determination of chlorpyrifos in any supernatant.

\subsection{XRD-Measurement}

As previously described [31], Clay-PTMA/-BTBA complexes having different loadings (0, $0.5 \mathrm{mmol}$ cationic surfactant/g clay) were measured for basal spacing using a Philips $1030 \mathrm{X}$-Ray diffractometer with CoKa radiation. These measurements were conducted at CRMD, CNRS-University, Orleans, France.

\subsection{Fourier Transform Infrared (FTIR)}

Following the procedure previously described [32] [33], $2 \mathrm{mg}$ of chlorpyrifos, or its complexes with clay or organo-clay was crushed with $98 \mathrm{mg}$ of $\mathrm{KBr}$ in the micro-mill. The mixture was transferred to a special cylinder with $1 \mathrm{~cm}$ diameter. The mixture was then compressed under vacuum and high atmospheric pressure (5 at) for $2 \mathrm{~min}$. The pellets were removed and transferred to a Petri dish for protection. The FTIR spectra were obtained using $\mathrm{KBr}$ pellets with Agilent Technologies, Cary 640 FTIR spectrometer. Spectra were recorded at room temperature in the range of $1800-1200 \mathrm{~cm}^{-1}$.

\subsection{Preparation of Organoclay Formulations of Chlorpyrifos}

The organoclay formulations of chlorpyrifos were prepared by dissolving appropriate amounts $(50 \mathrm{mg}$ ) of chlorpyrifos in $10 \mathrm{ml}$ methanol and transferring $2 \mathrm{ml}$ of the solution to a $180 \mathrm{mg}$ powdered clay, or organoclay suspended in $8 \mathrm{ml}$ methanol. The system was sealed and shaken for $4 \mathrm{~h}$ to ensure complete interaction between chlorpyrifos and clay or organo-clay. The solvent was evaporated under reduced pressure as previously described [34].

\subsection{Leaching Potential of Chlorpyrifos in Soil}

The leaching potential of chlorpyrifos in soil was tested using tin columns of the following dimensions: $10 \times 10 \mathrm{~cm}^{2}$ surface area and $25 \mathrm{~cm}$ height (Figure 2) [35] [36]. Each column was filled with $2 \mathrm{~L}$ air-dried sandy soil sieved through $2 \mathrm{~mm}$ mesh. The columns were shaken several times to ensure stable and homogenized sand distribution in the columns. The columns were then distributed into 6 groups, each group consisting of 5 columns, one group served as a control sample which did not receive chlorpyrifos. The other 5 groups each received one of the following formulations: Commercial 


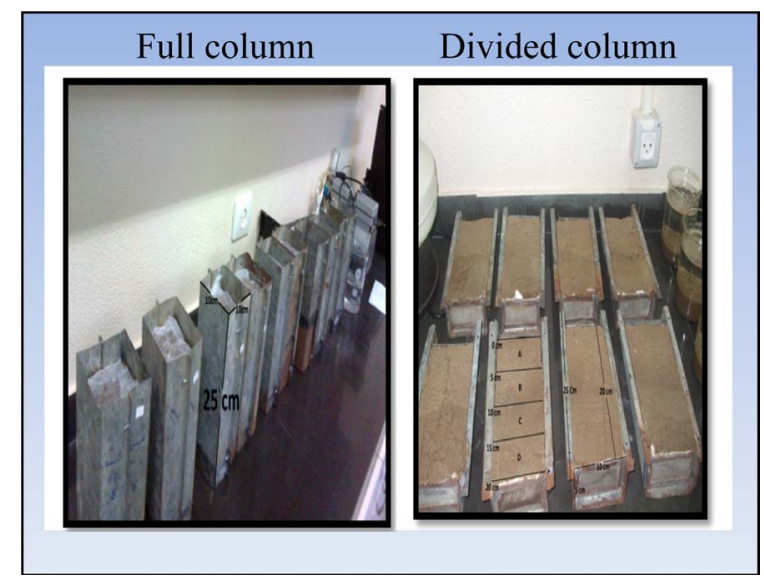

Figure 2. Column technique used for HPLC and bioassay techniques for determination of leaching potential in soil. Left photo shows full column filled with sandy soil and treated with chlorpyrifos and irrigated with water. Right photo shows the columns split lengthwise to form 2 pots.

formulation; clay, clay-PTMA; clay-BTMA; clay-BTBA. The formulation was sprayed onto the surface of the column. Each surface treated with the chlorpyrifos formulations received $1 \mathrm{mg}$ chlorpyrifos. Each column was carefully irrigated with $500 \mathrm{ml}$ distilled water (field capacity of water) applied in portions over 3 - 5 hours at 20 min intervals. The columns were left for $48 \mathrm{~h}$ in the laboratory for equilibration, then sliced lengthwise to form two pots of $10 \times 5 \times 25 \mathrm{~cm}$ each (Figure 2). One pot was used for chemical determination using HPLC, and the second was used for bioassay determination using $2^{\text {nd }}$ instar mosquito larvae bred in the laboratory as the test organism.

\subsection{HPLC Determination of Chlorpyrifos in Soil Layers}

One pot of the soil column was divided into 4 layers of $5 \mathrm{~cm}$ long (Figure 2). Each soil layer was transferred to a $2 \mathrm{~L}$ glass beaker containing $1000 \mathrm{ml}$ of distilled water. The soil samples were shaken for $3 \mathrm{~h}$ using a magnetic stirrer. The samples were left for $2 \mathrm{~h}$ for precipitation and two replicates of $5 \mathrm{ml}$ water were collected from each layer, centrifuged at 20,000 rpm and used for HPLC determination as mentioned above.

\subsection{Bioassay Determination of Chlorpyrifos in Soil Layers}

Dose-response relationship

Following the procedure described in El-Nahhal et al. [37] [38], series of chlorpyrifos concentrations in the range of $0.0-1 \mathrm{mg} / \mathrm{l}$ were prepared in $1 \mathrm{~L}$ distilled water. Ten mosquito larvae were added to each concentration. The number of dead larvae were recorded and taken as an indicator of chlorpyrifos concentration after $96 \mathrm{~h}$. \% mortality at each point was calculated according to Equation (2), El-Nahhal et al. [37]

$$
\% \text { mortality }=100 *\left(L_{c}-L_{t}\right) / L_{c}
$$

where $L_{c}$ and $L_{t}$ are the live cases in the control and treatment, respectively.

Regressing \% mortality versus concentrations at low range gives a linear relationship (Equation (3)). 
where $Y$ and $X$ are \% mortality and concentration $\mathrm{mg} / \mathrm{l}$ respectively, $a$ is the slope of the straight line and indicates the toxicity of chlorpyrifos.

Following the procedure described in the HPLC section, the soil water mixture was separated by filtration to obtain a clear solution. 10 mosquito larvae of $2^{\text {nd }}$ instar age were transferred to each container of the soil layer filtrate. Dead larvae were quantified as described above. \% mortality was calculated according to Equation (2) and application of Equation (3) enable determination of chlorpyrifos concentration in the soil layer.

\subsection{Statistical Analysis}

Each experiment was repeated 2 times with 5 replicates at each point each time. Mean and standard deviations were calculated for each point. For adsorption experiments error bars were presented in each isotherm, overlapping error bars indicate no statistically significant difference. The capacity and intensity of adsorption on the clay or organo-clay complexes were obtained by fitting the adsorption results to the Freundlich adsorption model $\left(q=K_{f} C_{e}^{1 / n}\right)$. The model can be transferred to a linear mode through $\log$ scale producing $\log q=\log K_{f}+1 / n \log C_{e}$, where $q$ represents the adsorbed amount $(\mathrm{mg} / \mathrm{g}), C_{e}$ is the remaining concentration in the solution, $K_{f}$ and $n$ are Freundlich constants indicating capacity and intensity of adsorption respectively. ANOVA was used to detect significant differences at the 0.05 level.

\section{Results and Discussion}

The organic cations used in this study (Figure 1) are surface active agents, sold at room temperature [28]. BTMA, PTMA, BTEA and BTBA contain aromatic ring and aliphatic moiety in their structures.

The aromatic ring may enhance the $\pi$ - $\pi$ interactions with chlorpyrifos. At low tested concentration, they do not have toxicity to different organism. Moreover, these substances can be bound to clay fraction in soil or react with humic and/or fulvic acids and make larger organic molecules that interact with organic pollutants in soil or aquatic systems accordingly, they are environmentally friendly compounds. Similar observation were reported previously [39]. So far, using these organoclays as adsorbents may further enhance the adsorption of chlorpyrifos and reduce their release in the environment. Moreover, analysis of carbon contents in the organoclays indicated that it contained organic cations below the cation exchange capacity of the clay minerals (data not shown). Detailed description of the mechanism for the formation of clay-organic cation complexes are shown in El-Nahhal and Safi [40].

In addition, the tested soil in this study had the following physicochemical properties: $\mathrm{pH}$ value $(7.0 \pm 0.2)$, $\mathrm{EC}$ value $(0.95 \pm 0.03) \mathrm{ms} / \mathrm{cm}, \mathrm{CaCO}_{3}$ value $(0.05 \%)$, clay fraction $(3 \%)$ and organic matter value is $(1.73 \% \pm 0.07 \%)$.

\subsection{Adsorption of Chlorpyrifos}

The relationship between peak areas and corresponding standard concentration of 
chlorpyrifos gave linear relationship. Regression analysis showed a correlation coefficient $\left(\mathrm{R}^{2}\right)$ of 0.998 indicating a strong positive association, validity and the suitability of the method used. Accordingly the linear equation was used to determine the concentration of chlorpyrifos in the unknown samples in the supernatants by HPLC. Adsorption of chlorpyrifos on the different clay and organo-clay complexes is shown in Figure 3. It demonstrates that a small amount of chlorpyrifos was adsorbed on unmodified clay similar results were previously reported [41] who revealed low adsorbed amount of chlorpyrifos on Montmorillonite.

Modifying clay surfaces with different organic cations resulted in enhanced adsorption. Moreover, modifying the clay surfaces with the largest organic cation (i.e. BTBA) resulted in further enhancement of chlorpyrifos adsorption. The explanation of these results is that the clay surface without modification has hydrophilic properties due to the presence of inorganic cations, whereas modification of the clay surfaces with organic cations (e.g. PTMA) creates a micro-hydrophobic environment on the clay surface facilitating the adsorption of chlorpyrifos. Our results agree with Nir et al., [42] who revealed that pre adsorbing the clay minerals with aromatic organic cations enhanced the adsorption of non ionic organic molecules from water. Further supports to our results come from the findings of Baglieri et al., [43] who reported similar phenomena in other cases. Moreover, modifying the clay surface with larger cations (e.g. BTBA) created a more hydrophobic environment on the clay surfaces hence more adsorption was observed. This suggestion is further supported by a study of Rubin et al. [44] who found that using hexadecyltrimethyl ammonium (HDTMA) created a hydrophilic layer that allowed chlorophenols to be partitioned between water and the organo-clay according to log Kow value. Moreover, adsorption mechanisms of organic cations and clay surfaces are shown below.

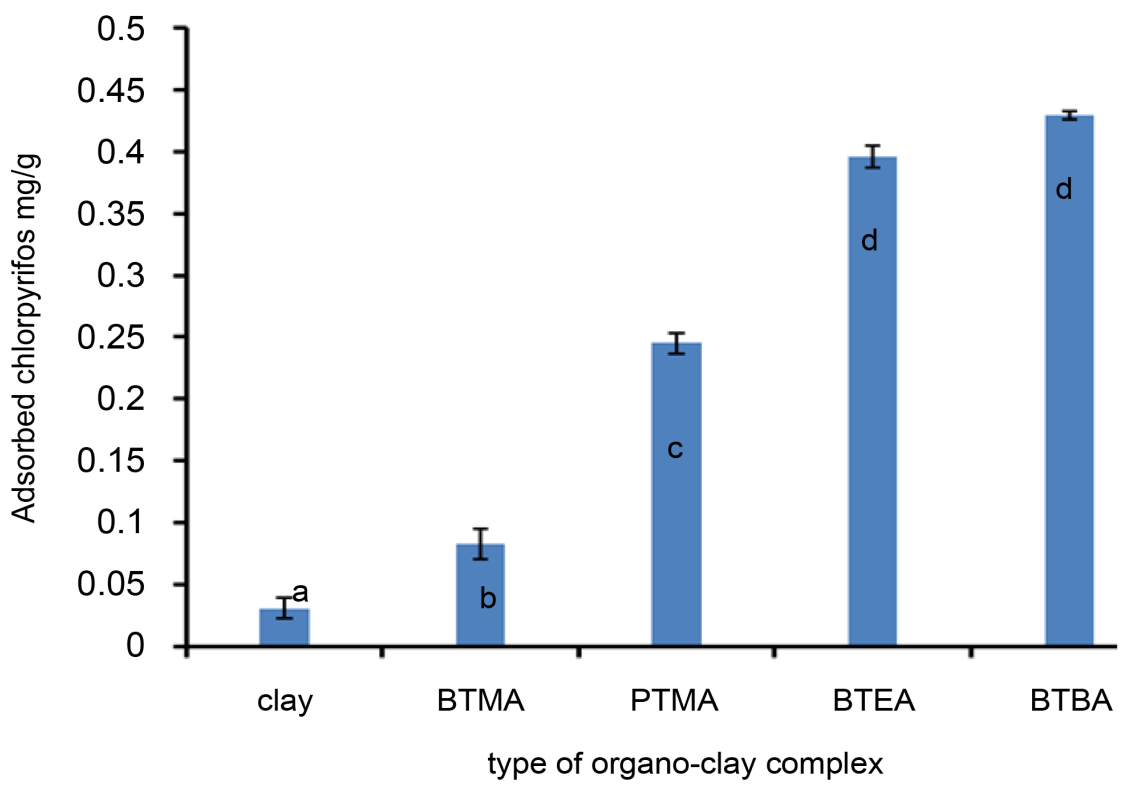

Figure 3. Adsorption of chlorpyrifos on different organo-clay complexes. Error bars represent standard deviations. Columns labeled d are not significantly different at 0.05 level of significance. 


\subsection{Adsorption Mechanisms}

XRD-Measurements showed that adsorption of PTMA, BTMA, BTEA and BTBA molecules a loading of $0.5 \mathrm{mmol} / \mathrm{g}$ clay resulted in increasing the basal spacing of clay layers. For instance, the basal spacing is approximately 11.9 A in clay (no organic cationic adsorbed on clay surfaces). This result agrees with Mac Ewan and Wilson [45] who found similar basal spacing for $\mathrm{Na}^{+}$Montmorillonite. Pre-adsorption of the clay mineral with a smaller organic cation (e.g PTMA), at $0.5 \mathrm{mmol} / \mathrm{g}$ clay increasing the basal spacing to 14.09 A, whereas using a larger organic cation BTBA, the basal spacing increased up to 15.9 A. These results agree with El-Nahhal [31] who found similar basal spacing for organic cation adsorbed on Montmorillonite. These results suggest that the basal spacing is increased as the size of the aliphatic part of the organic cation increased (Figure 1). For instance, the nearly similar basal spacing of clay modified with PTMA or BTMA may due to the fact that the quaternary ammonium substituted with- $\mathrm{CH} 3$ in both cases. Modifying the clay surface with BTBT increased in the basal spacing, this is probably due to the fact that the quaternary ammonium saturated with three aliphatic groups $\left(-\mathrm{CH}_{2} \mathrm{CH}_{2} \mathrm{CH}_{2} \mathrm{CH}_{3}\right)$. These groups may be oriented in different angles, accordingly tremendous increases in the basal spacing was observed. Consequently, modification of the clay surfaces with different organic cation may lead to the formation of micro-pores having different size according to the chemical structure and molecular size of the organic cation and the degree of coverage of the surfaces. Accordingly, modifying the clay surface with a smaller size organic cation such as PTMA or BTMA, the phenyl rings and the aliphatic parts may be oriented parallel to clay layers (Figure 4) producing a smaller room (basal spacing). This position may not allow/maximize $\pi$-electrons to interact with chlorpyrifos through $\pi-\pi$ interaction as obvious in Figure 4(a). Orientation

(a)

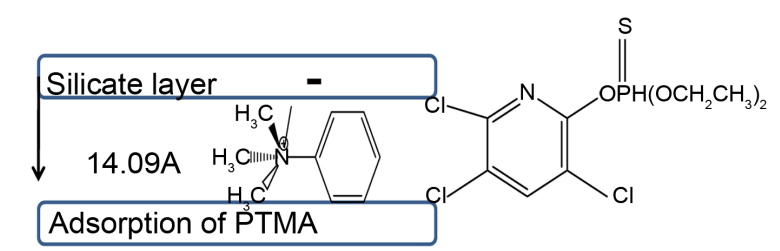

(b)

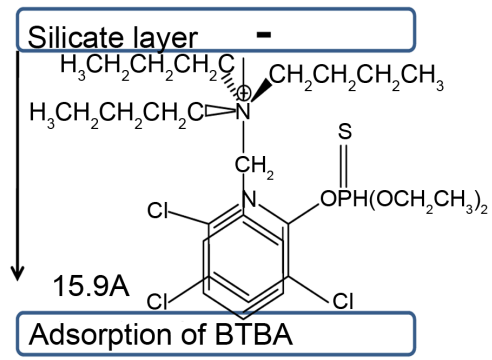

Figure 4. Schematic view of interaction of chlorpyrifos on clay saturated with (a) a smaller organic cation (e.g. PTMA), and (b) a larger organic cation (BTBA). 
of PTMA molecules on montmorillonite surfaces was previously reported [46]. For the case of modifying the clay surfaces with BTBA a larger basal spacing was obtained due to the large size of BTBA and the orientation of aliphatic and aromatic rings. This position may allow/maximize $\pi$-electrons to interact with chlorpyrifos through $\pi-\pi$ interaction as obvious in Figure 4(b). This situation may result in either formation of micro-pores on the clay surfaces that accommodate more molecules of chlorpyrifos or better interaction between the phenyl rings through $\pi-\pi$ interaction and/or hydrogen bonding of pre-adsorbed organic cation and chlorpyrifos molecules. This suggestion is supported by the results of Stevens and Anderson [46] who highlighted the $\pi-\pi$ interactions. Schematic diagram of Chlorpyrifos interaction with clay modified with a smaller organic cation (e.g. PTMA) and a larger organic cation (BTBA) is shown in Figure 4. It can be concluded that the interaction of chlorpyrifos with clay-PTMA seems weak due to the smaller basal spacing (Figure 4(a)) accordingly low adsorption was occur on clay-PTMA (Figure 3). At clay-BTBA (Figure 4(b)), the basal spacing is larger than the upper case accordingly the $\pi-\pi$ interactions is freely occurred accordingly more adsorption was observed (Figure 3 ). In addition hydrogen bonding may also influence the interaction between chlorpyrifos molecules and clay-PTMA due to a smaller basal spacing. In this case the aliphatic part of chlorpyrifos may have good position to interact with clay-PTMA accordingly high adsorption was occurred. This hypothesis was also supported by recent work of Olivella et al. [47] who emphasize the effects of $\pi$ - $\pi$ interaction, hydrogen bonding and hydrophobic effects as shown for the case of clayPTMA (Figure 4(a)).

\subsection{Adsorption Isotherms}

The adsorption isotherms of chlorpyrifos on bentonite (clay), Clay-BTMA, Clay-PTMA, Clay-BTEA, and Clay-BTBA complexes are shown in Figure 5. These isotherms were generated at aqueous chlorpyrifos concentrations up to its solubility limit in water (1 $\mathrm{mg} / \mathrm{L})$. As expected, chlorpyrifos was poorly adsorbed on clay alone, whereas adsorption on clay pre adsorbed with PTMA, BTMA, BTEA or BTBA at a load of $0.5 \mathrm{mmol} / \mathrm{g}$ resulted in larger adsorbed amounts of chlorpyrifos than on clay alone. These data are in agreement with previous results reported by Jaynes and Boyd [48] El-Nahhal and Safi [49] who confirmed transformation of clay surfaces from hydrophilic to hydrophobic by pre-adsorbing alkyl ammonium. Moreover, increasing chlorpyrifos concentration in the solution results in a further increase in the adsorbed amounts of chlorpyrifos in all cases. This suggests high affinity of the surface to adsorb chlorpyrifos. However the magnitude of affinity differs between organoclay complexes. The lowest magnitude was observed on clay without surface modification and the highest magnitude on Clay-BTBA. The explanation of these results is related to the hydrophilic nature of the clay and hydrophobic nature of chlorpyrifos, more elaboration on this topic has been given above. Fitting the data in Figure 5 to the Freundlich adsorption model provides the adsorption parameters, $K_{f}$ and $n$, (Table 1 ) that indicated capacity and intensity of adsorption respectively. It can be seen that $K_{f}$ values ranged from 0.24 in the case of 


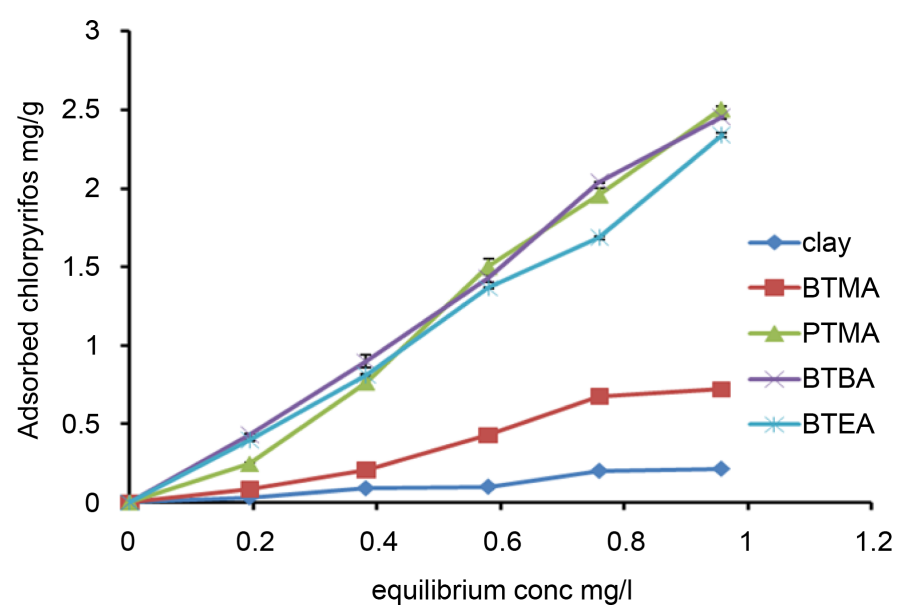

Figure 5. Adsorption of chlorpyrifos on clay and organo-clays. Error bars represent standard deviations. Overlapping of error bars indicates no significant differences at 0.05 level.

Table 1. Adsorption parameters of chlorpyrifos on clay and different organo-clays.

\begin{tabular}{cccc}
\hline Adsorbent & $K_{f}$ & $n$ & $R^{2}$ \\
\hline Clay & 0.24 & 0.82 & 0.954 \\
Clay-BTMA & 1.06 & 0.67 & 0.98 \\
Clay-PTMA & 11.72 & 0.51 & 0.957 \\
Clay-BTEA & 4.59 & 0.86 & 0.986 \\
Clay-BTBA & 5.81 & 0.83 & 0.994 \\
\hline
\end{tabular}

clay alone to 11.72 in the clay modified with PTMA, clay modified with BTBA also showed a high value of $K_{f}(5.81)$ indicating several magnitudes of adsorption capacity. The values of $n$ are quite similar except Clay-PTMA and Clay-BTMA have lower values. The explanation for these variations is that the clay surfaces are not fully saturated with organic cation up to the cation exchange capacity. Therefore chlorpyrifos molecules tend to interact directly with clay surfaces through water bridges as demonstrated in previous studies [32] and with organic cation in the clay surface. In these cases the interaction tends to occur via $\pi-\pi$ interactions with phenyl rings due to the smaller size of the cations. El-Nahhal et al., [50] demonstrated the effects of smaller molecular size of the organic cations in further enhancing the removal of organic molecules from water systems via adsorption. In addition further elaboration of the interactions on the clay surfaces are given below in the FTIR section.

\subsection{FTIR Spectrum of Chlorpyrifos with Clay or Organo-Clay Complexes}

Detailed information on the chlorpyrifos interaction with clay or organo-clay surfaces was obtained via FTIR spectroscopy. Figure 6 shows spectra of chlorpyrifos in its free form, adsorbed to the clay alone; adsorbed to clay modified with PTMA and adsorbed to clay modified with BTBA. The two peaks at 1549.425 and $1410.152 \mathrm{~cm}^{-1}$ in the spec- 


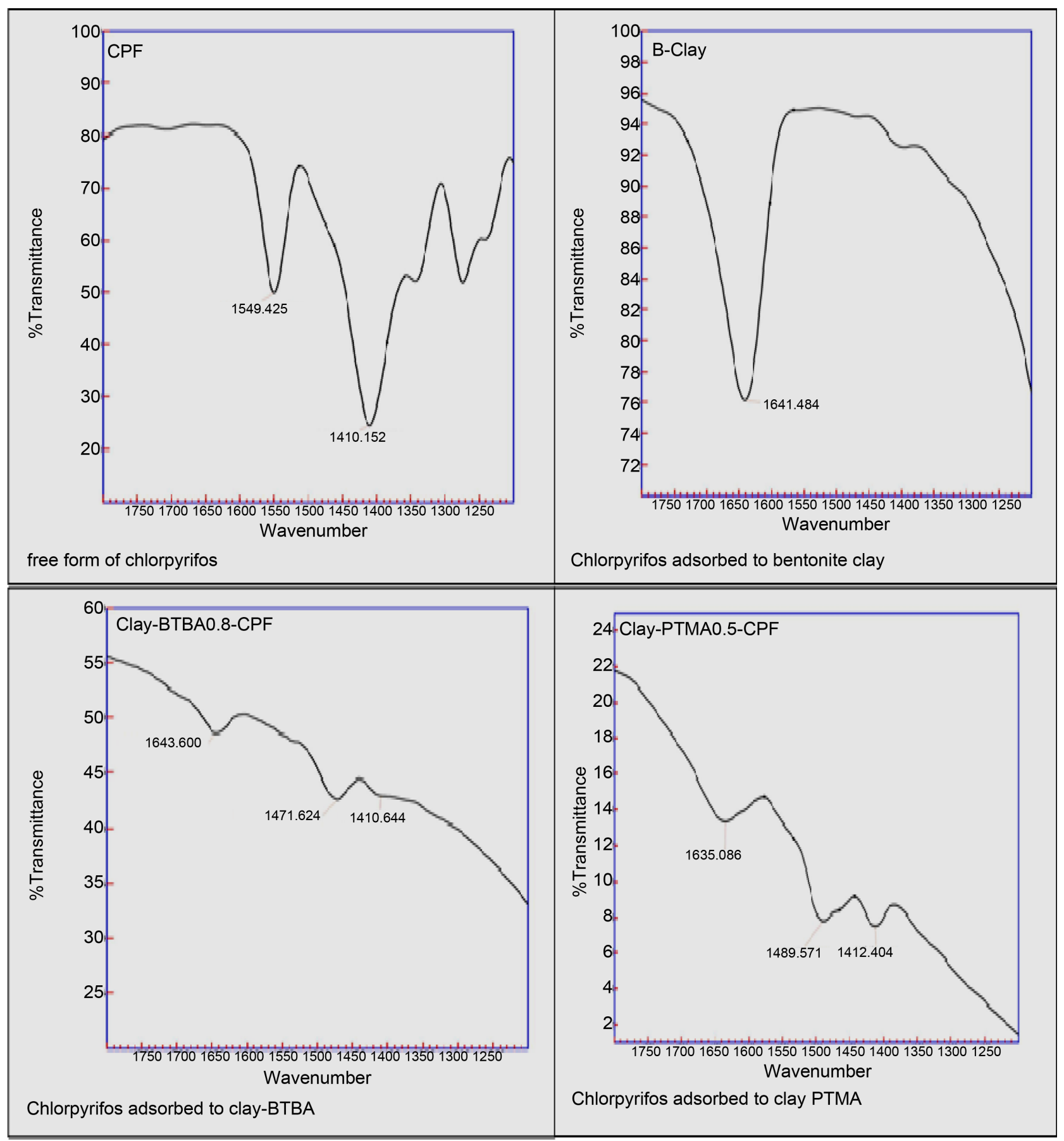

Figure 6. FTIR results. Chlorpyrifos in its free form (top left), adsorbed to clay (top right), adsorbed to clay-BTBA (bottom left) and adsorbed to clay-PTMA (bottom right). Unit of wave number is $\mathrm{cm}^{-1}$.

trum of free chlorpyrifos were assigned to the stretching vibrations of the $\mathrm{CH}(\mathrm{Cl}) 3$ on the phenyl ring $\left(1549.425 \mathrm{~cm}^{-1}\right)$ and $\mathrm{N}-\mathrm{H}$ of the anilidic group $\left(1410.125 \mathrm{~cm}^{-1}\right)$. Similar vibrations have been reported previously [51]. The main differences among the spectra are as follows: 1) the peak at $1549.425 \mathrm{~cm}^{-1}$ of the free chlorpyrifos was shifted to a higher wave number at $1641.484 \mathrm{~cm}^{-1}$ (clay), $1643.8 \mathrm{~cm}^{-1}$ (Clay-BTBA) and 1635.08 
$\mathrm{cm}^{-1}$ (clay-PTMA); 2) the peak at $1410.152 \mathrm{~cm}^{-1}$ in the free form of chlorpyrifos disappeared in clay, shifted to higher wave numbers at 1471.624, with an inverted peak at 1450 (clay-BTBA), and $1489.571 \mathrm{~cm}^{-1}$ with another peak at $1412 \mathrm{~cm}^{-1}$. These shifts indicate that pyridyl group of chlorpyrifos molecules interact more strongly with the phenyl ring of the organo-clay complex. Moreover, the hydrophobic side-chain groups (CH3-CH2-)2 of the chlorpyrifos molecule reflect with the CH3-(e.g. PTMA, BTMA); $\mathrm{CH} 3-\mathrm{CH} 2$-(e.g. BTEA); or CH3-CH2-CH2-CH2 (e.g BTBA). The effect is more strong in the case of Clay-BTBA due to more hydrophobic interaction. In the case of clay alone, the interaction seems to be via hydrophilic interaction through water molecule bridge (hydrogen bonding between $\mathrm{P}-\mathrm{O}-\mathrm{H}-\mathrm{O}$-clay). Regardless to the fact that the shift seem to be large but is is a hydrophilic interaction and immediately become very week under more hydrophilic environment (aqueous solution) accordingly more leaching was onserbed with clay formulations. Our results agree with Schmidt et al., [52] who revealed higher shifts due to the hydrophobic side-chain groups interaction with other molecules. The disappearance of the peak at $1410.152 \mathrm{~cm}^{-1}$ when chlorpyrifos interacts with the clay surface without modification indicates disappearance of the $\pi-\pi$ interaction and/or hydrophobic interaction. In accord with the data in Figure 4. Modifying the clay surface with PTMA or BTBA resulted in large shifts to higher wave numbers with appearance of other peaks indicating strong interaction. These results are supported by the larger adsorbed amount of chlorpyrifos on organo-clays than clay without modification. More support for our results comes from the recent work of Olivella et al. [47] who emphasized the effects of $\pi-\pi$ interaction, hydrogen bonding and hydrophobic effects as shown for the case of clay-PTMA (Figure 4(a)).

\subsection{Release and Leaching Potential of Chlorpyrifos in Soil Columns}

Release and leaching potential of chlorpyrifos from the different formulations in soil columns are shown in Figure 7 and Figure 8. The HPLC determination of the release

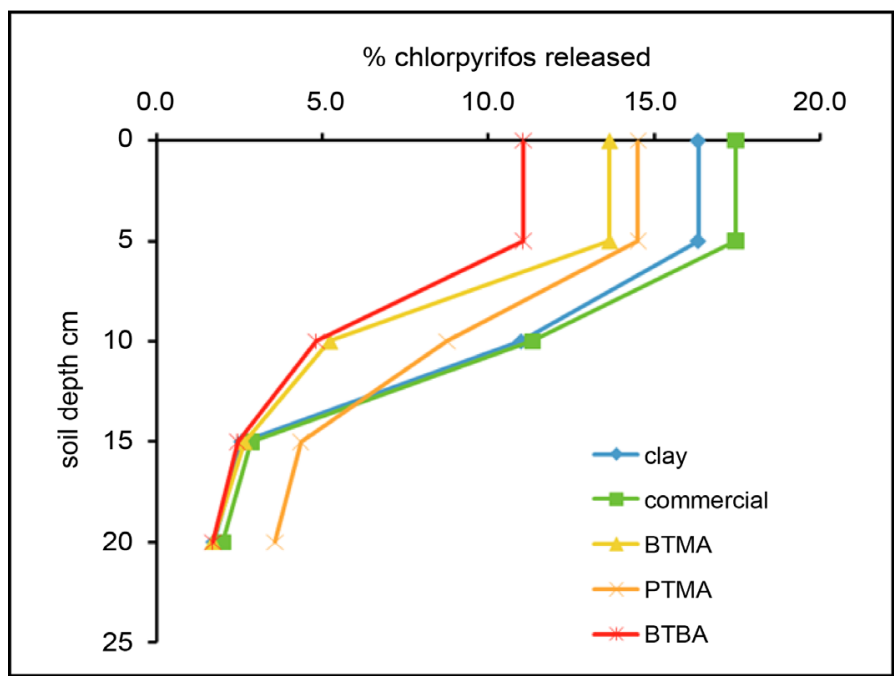

Figure 7. HPLC determination of released fraction of chlorpyrifos from different formulations in sandy soil in Gaza. 


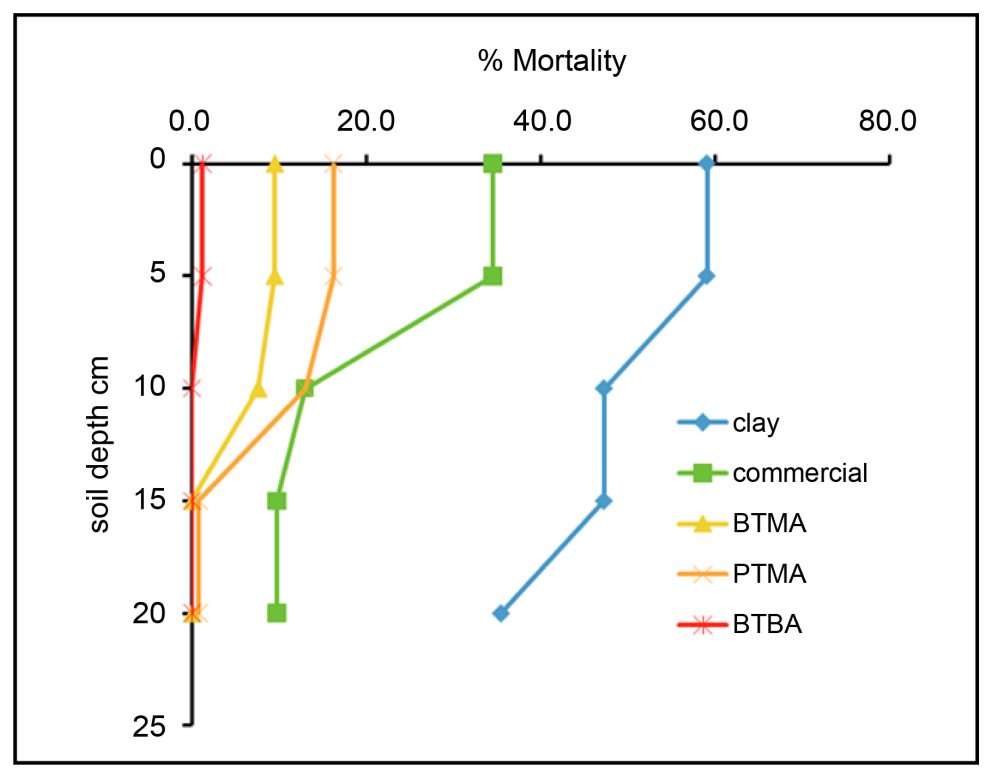

Figure 8. Bioassay determination of released fraction of chlorpyrifos from different formulations in sandy soil in Gaza.

and leaching of chlorpyrifos (Figure 7) and bioassay techniques (Figure 8) indicate that chlorpyrifos is released in different fractions from different formulations. However, the trend is similar in all cases. It can be seen that the released fraction of chlorpyrifos from clay and commercial formulations are $16.5 \%$ and $18.5 \%$ respectively, whereas the released fraction from organo-clays are below $15 \%$ of the total concentration. In the case of clay-BTBA, the released fraction of chlorpyrifos was about $10 \%$. Furthermore, considerable concentrations of chlorpyrifos were detected in deeper depths in all cases. The lowest fraction ( $\sim 5 \%$ release) was found in the soil layer $15-20 \mathrm{~cm}$, indicating high leaching potential. An interesting finding of this study is that organo-clay formulations have a lower leaching potential compared to commercial or clay formulations. In accord with the adsorption results (Figure 3 ) This suggests that organo-clay formulations of chlorpyrifos may remain in the topsoil layer to provide effective insect control while protecting ground water and reducing residues in deeper soil levels. Nevertheless, in all cases below $2.5 \%$ of the released fraction of chlorpyrifos was detected at deeper soil depth $(15-20 \mathrm{~cm})$. The bioassay technique (Figure 8) showed a high percentage mortality in mosquito larvae due to the released fraction of chlorpyrifos from clay and commercial formulations. The high percentage mortality of mosquitoes (60\%) indicates that a high fraction of chlorpyrifos is released from clay and the commercial formulation and consequently their potential for leaching into the soil profile is high. These results are in accord with recent report Shah et al. [53] who found that chlorpyrifos has been shown to be the most toxic insecticide against southern house mosquito (The $\mathrm{Cu}$ lex quinquefaciatus Say). In contrast, organo-clay formulations released a significantly lower fraction of chlorpyrifos and consequently a lower percentage mortality of mosquito larvae was observed. Moreover, the leaching potential of organo-clay formulations was restricted to the top soil layer. Clay-BTBA showed promising results in re- 
stricting chlorpyrifos release and leaching potential.

The differences between the data of HPLC determination (Figure 7) and bioassay determination (Figure 8) can be explained by the fact that HPLC can only quantify the concentration of chlorpyrifos in the soil layer, whereas bioassay detects the effect corresponding to the concentration. Moreover, the response also depends on the sensitivity of the tested organism. Concentrations determined by chemoassay usually differ from those obtained by bioassay due to variability in the sensitivity of the tested organisms, age of the organisms, testing conditions and precision of the methods used. However, our results agree with previous reports [31], [33] who found 10\% - 15\% difference between bioassay and chemoassay for determination of herbicide concentrations in soil profiles. Leaching depth has the following order Clay-BTBA $<$ Clay-BTMA $<$ Clay-PTMA $<$ Com $<$ Clay.

Its is of great importance to mention that toxicity tests of organo-clay without chlorpyrifos to mosquitoes showed no mortality during the experimental period.

\section{Conclusions}

This study presents an attempt to develop a controlled release formulation of chlorpyrifos to reduce leaching of the compound into soil and water. Our approach involved the following aspects:

1) Modification of the clay surface from hydrophilic to hydrophobic by pre-adsorbing to it an organic cation whose structure would enable optimal interactions between chlorpyrifos molecules and the surface sites of the organo-clay complexes.

2) Optimizing the interaction of chlorpyrifos molecules with the organic cation on the clay surface through selection of the suitable organic cation that has chemical structure able to match the targeted molecule (chlorpyrifos) and optimize the clay surface coverage of organic cation.

The amounts of chlorpyrifos adsorbed on the organo-clay complexes followed the sequence $\mathrm{BTBA}=\mathrm{PTMA}>\mathrm{BTEA}>\mathrm{BTMA}>$ clay. Basal spacing results emphasize the formation of suitable micro-porse for accommodation of chlorpyrifos molecules.

Release and leaching potential of chlorpyrifos were reduced when formulated with organo-clay complexes according to the sequence of its adsorption. Clay-BTBA showed the best advantages (large adsorption, strong interaction, and best micro-pores fit) among the tested organoclay complexes. HPLC and bioassay techniques were effective and strong tools for determination of release and leaching potential of chlorpyrifos in soil.

The results of this study confirm that organo-clay formulations of chlorpyrifos reduce leaching of this insecticide into soil and water, and therefore have the potential to reduce its negative impacts on human health and the environment.

\section{Acknowledgements}

Dr. Y. El-Nahhal acknowledges Alexander von Humboldt Stiftung Foundation Fellowship Grant no IV-PAL/1104842 STP, Germany. Special thanks go to Prof. Dr. G. lagaly 
at Kiel University, Prof. G. Shourrmman, and Dr. U. Schocknechet at BAM, Germany. Special thanks go to Mrs. Julie Webb.

\section{References}

[1] Tomlin, C.D.S. (2006) The Pesticide Manual, A World Compendium, 14th Edition British Crop Protection Council. Alton, Hampshire, 186-187.

[2] El-Nahhal, Y. (2004) Contamination and Safety Status of Plant Food in Arab Countries. Journal of Applied Science, 4, 411-417. http://dx.doi.org/10.3923/jas.2004.411.417

[3] Phillips, P.J. and Bode, R.W. (2004) Pesticides in Surface Water Runoff in South-East New York State, USA: Seasonal and Storm Flow Effects on Concentrations. Pest Management Science, 60, 531-543.

[4] Becker, K., Seiwert, M., Angerer, J., Kolossa-Gehring, M., Hoppe, H.W., Ball, M., Schulz, C., Thumulla, J. and Seifert, B. (2006) GerES IV Pilot Study: Assessment of the Exposure of German Children to Organophosphorus and Pyrethroid Pesticides. International Journal of Hygiene and Environmental Health, 209, 221-233.

[5] Rahmanikhah, Z., Abbas, E.S., Bahramifar, N. and Bousjien, Z.Sh. (2010) Organophosphorous Pesticide Residues in the Surface and Ground Water in the Southern Coast Watershed of Caspian Sea Iran. World Applied Sciences Journal, 9, 160-166.

[6] Angioni, A., Dedola, F., Garau, A., Sarais, G., Cabras, P. and Caboni, P. (2011) Chlorpyrifos Residues Levels in Fruits and Vegetables after Field Treatment. Journal of Environmental Science and Health. Part B, 46, 544-549.

[7] Schecter, A., Papke, O., Isaac, J., Hrimat, N., Neiroukh, F., Safi, J. and El-Nahhal, Y. (1997) 2,3,7,8 Chlorine Substituted Dioxins and Dibenzofuran Congeners in 2,4-D, 2,4,5-T and Pentachlorophenol. Organohalogen Compounds, 32, 51-55.

[8] Harnly, M., McLaughlin, R., Bradman, A., Anderson, M. and Gunier, R. (2005) Correlating Agricultural Use of Organophosphates with Outdoor Air Concentrations: A Particular Concern for Children. Environmental Health Perspectives, 113, 1184-1189.

[9] Zhong, G., Xie, Z., Cai, M., Moller, A., Sturm, R., Tang, J., Zhang, G., He, J. and Ebinghaus, R. (2012) Distribution and Air-Sea Exchange of Current-Use Pesticides (CUPs) from East Asia to the High Arctic Ocean. Environmental Science \& Technology, 46, 259-267. http://dx.doi.org/10.1021/es202655k

[10] Garbarino, J.R., Snyder-Conn, E., Lieker, T.J. and Hoffman, G.L. (2002) Contaminants in Arctic Snow Collected over Northwest Alaskan Sea Ice. Water, Air, \& Soil Pollution, 139, 183-214. http://dx.doi.org/10.1023/A:1015808008298

[11] Hore, P., Robson, M., Freeman, N., Zhang, J., Wartenberg, D., Ozkayna, H., Tulve, N., Sheldon, L., Needham, L., Barr, D. and Lioy, P.J. (2005) Chlorpyrifos Accumulation Patterns for Child-Accessible Surfaces and Objects and Urinary Metabolite by Children for 2 Weeks after Crack-and-Crevice Application. Environmental Health Perspectives, 113, 211-219. http://dx.doi.org/10.1289/ehp.6984

[12] Morgan, M.K., Sheldon, L.S., Croghan, C.W., Jones, P.A., Robertson, G.L., Chuang, J.C., Wilson, N.K. and Lyu, C.W. (2005) Exposures of Preschool Children to Chlorpyrifos and Its Degradation Product 3,5,6-Trichloro-2-Pyridinol in Their Everyday Environments. Journal of Exposure Analysis and Environmental Epidemiology, 15, 297-309. http://dx.doi.org/10.1038/sj.jea.7500406

[13] Safi, J., Abu Foul, N., El-Nahhal, Y. and El-Sebae, A. (2002) Monitoring of Pesticide Residues on Cucumber, Tomatoes and Strawberries in Gaza Governorates, Palestine. Nahrung/ Food, 46, 34-49. 
http://dx.doi.org/10.1002/1521-3803(20020101)46:1<34::AID-FOOD34>3.0.CO;2-W

[14] Safi, J., Awad, Y. and El-Nahhal, Y. (2014) Bioremediation of Diuron in Soil and by Cyanobacterial Mat. American Journal of Plant Sciences, 5, 1081-1089.

http://dx.doi.org/10.4236/ajps.2014.58120

[15] Schecter, A., Papke, O., Ryan, J., Furst, P., Isaac, J., Hrimat, N., Neiroukh, F., Safi, J., El-Nahhal, Y., Abu El-Haj, S., Avni, A., Richter, E., Chuwers, P. and Fischbein, A. (1997) Dioxins, Dibenzofurans and PCBs in Human Blood, Human Milk and Food from Israel, The West Bank and Gaza. Organohalogen Compounds, 33, 457-461.

[16] Anderson, T.D. and Lydy, M.J. (2002) Increased Toxicity to Invertebrates Associated with a Mixture of Atrazine and Organophosphate Insecticides. Environmental Toxicology and Chemistry, 21, 1507-1515. http://dx.doi.org/10.1002/etc.5620210724

[17] USEPA (US Environmental Protection Agency) (2011) Chlorpyrifos Facts. http://www.epa.gov/oppsrrd1/REDs/factsheets/chlorpyrifos_fs.htm

[18] Belden J.B., Gilliom, J.R. and Lydy, J.M. (2007) How Well Can We Predict the Toxicity of Pesticide Mixtures to Aquatic Life. Integrated Environmental Assessment and Management, 3, 364-372. http://dx.doi.org/10.1002/ieam.5630030307

[19] Jin, Y., Liu, Z., Peng, T. and Fu, Z. (2015) The Toxicity of Chlorpyrifos on the Early Life Stage of Zebrafish: A Survey on Endpoints at Development, Locomotor Behavior, Oxidative Stress and Immunotoxicity. Fish \& Shellfish Immunology, 43, 405-414. http://dx.doi.org/10.1016/j.fsi.2015.01.010

[20] Kais, B., Stenel, D., Batel, A. and Braunbech, T. (2015) Acetylcholinesterase in Zebrafish Embryos as a Tool to Identify Neurotoxic Effects in Sediments. Environmental Science and Pollution Research International, 22, 16329-16339. http://dx.doi.org/10.1007/s11356-014-4014-1

[21] EL-Nahhal, Y., EL-Najjar, Sh. and Afifi, S. (2015) Impact of Organic Contamination on Some Aquatic Organisms. Toxicology International, 22, 45-53. http://dx.doi.org/10.4103/0971-6580.172256

[22] El-Nahhal, Y. (2016) Biochemical Changes Associated with Long Term Exposure to Pesticide among Farmers in the Gaza Strip. Occupational Diseases and Environmental Medicine, 4, 72-82. http://dx.doi.org/10.4236/odem.2016.43009

[23] Sindi, R.A., Harris, W., Arnott, G., Flaskos, J., Lloyd Mills, C. and Hargreaves, A.J. (2016) Chlorpyrifos- and Chlorpyrifos Oxon-Induced Neurite Retraction in Pre-Differentiated N2a Cells Is Associated with Transient Hyperphosphorylation of Neurofilament Heavy Chain and ERK 1/2. Toxicology and Applied Pharmacology, 308, 20-31. http://dx.doi.org/10.1016/j.taap.2016.08.008

[24] Želježić, D., Mladinić, M., Žunec, S., LucićVrdoljak, A., Kašuba, V., Tariba, B., Živković, T., Marjanović, A.M., Pavičić, I., Milić, M., Rozgaj, R. and Kopjar, N. (2016) Cytotoxic, Genotoxic and Biochemical Markers of Insecticide Toxicity Evaluated in Human Peripheral Blood Lymphocytes and an HepG2 Cell Line. Food and Chemical Toxicology, 96, 90-106. http://dx.doi.org/10.1016/j.fct.2016.07.036

[25] Chen, S., Chen, M., Wang, Z., Qiu, W., Wang, J., Shen, Y., Wang, Y. and Ge, S. (2016) Toxicological Effects of Chlorpyrifos on Growth, Enzyme Activity and Chlorophyll a Synthesis of Freshwater Microalgae. Environmental Toxicology and Pharmacology, 45, 179-186. http://dx.doi.org/10.1016/j.etap.2016.05.032

[26] MoA (Ministry of Agriculture) (2013) Department of Plant Protection. Annual Report, Gaza.

[27] El-Nahhal, Y. and Lagaly, G. (2005) Salt Effects on the Adsorption of a Pesticide on Modified Bentonite. Colloid and Polymer Science, 283, 968-974. 
http://dx.doi.org/10.1007/s00396-004-1244-7

[28] El-Nahhal, Y., Nir, S., Polubesova, T., Margulies, L. and Rubin, B. (1997) Organo-Clay Formulations of Alachlor: Reduced Leaching and Improved Efficacy. Proceedings of Brighton Crop Protection Conference, Brighton, November 1997, 21-26.

[29] El-Nahhal, Y. (2003) Adsorptive Behavior of Acetochlor on Organoclay Complexes. Bulletin of Environmental Contamination and Toxicology, 70, 1104-1111. http://dx.doi.org/10.1007/s00128-003-0096-Z

[30] El-Nahhal, Y. (2002) Adsorptive of Chlorpyrifos on Organoclay Complexes: Influence of Salt Concentration. In: Ottner, F. and Gier, S., Eds., Berichte der Deutschen Ton-und To nmineralgruppe e. $V$, Band 9, Beitrage zur Jahrestagung, Wien, 17-30.

[31] El-Nahhal, Y. (2003) Adsorption Mechanism of Chloroacetanilide Herbicides to Modified Montmorillonite. Journal of Environmental Science and Health Part B, 38, 591-604. http://dx.doi.org/10.1081/PFC-120023517

[32] El-Nahhal, Y., Nir, S., Polubesova, T., Margulies, L. and Rubin, B. (1998) Leaching, Phototoxicity and Weed Control of New Formulation of Alachlor. Journal of Agricultural and Food Chemistry, 46, 3305-3313. http://dx.doi.org/10.1021/jf971062k

[33] El-Nahhal, Y., Lagaly, G. and Rabinovitz, O. (2005) Organo-Clay Formulations of Acetochlor: Effect of High Salt. Journal of Agricultural and Food Chemistry, 53, 1620-1624. http://dx.doi.org/10.1021/jf040383a

[34] El-Nahhal, Y. (2003) Persistence, Mobility, Efficacy and Safety of Chloroacetanilide Herbicide Formulation under Field Conditions. Environmental Pollution, 124, 33-38. http://dx.doi.org/10.1016/S0269-7491(02)00431-1

[35] El-Nahhal, Y. (2004) Leaching Behavior of Metolachlor in Soil. Journal of Environmental Engineering \& Science, 3, 187-194. http://dx.doi.org/10.1139/s03-075

[36] El-Nahhal, Y., Abadsa, M. and Affifi, S. (2014) Leaching Potential of Diuron and Linuron in Gaza Soils. American Journal of Plant Sciences, 5, 4040-4049. http://dx.doi.org/10.4236/ajps.2014.526422

[37] El-Nahhal, Y., EL-dahdouh, N., Hamdona, N. and Alshanti, A. (2016) Toxicological Data of Some Antibiotics and Pesticides to Fish, Mosquitoes, Cyanobacterial Mats and to Plants. Data in Brief, 6, 871-880. http://dx.doi.org/10.1016/j.dib.2016.01.051

[38] EL-Nahhal, Y., Kerkez, M.F.S. and Abu Heen, Z. (2015) Toxicity of Diuron, Diquat and Terbutryn Cyanobacterial Mats. Ecotoxicology and Environmental Contamination, 10, 71 82. http://dx.doi.org/10.5132/eec.2015.01.11

[39] Nir, S., El-Nahhal, Y., Undabeytia, T., Rytwo, G., Polubesova, T., Mishael, Y., Rabinovitz, O. and Rubin, B. (2006) Clays and Pesticides. In: Bergaya, F., Theng, B.K.G. and Lagaly, G., Eds., Handbook of Clay Science, Elsevier, Amsterdam, 677-691. http://dx.doi.org/10.1016/S1572-4352(05)01021-4

[40] El-Nahhal, Y. and Safi, J. (2004) Adsorption Behavior of Phenanthrene on Organoclays under Different Salinity Levels. Journal of Colloid and Interface Science, 269, 265-273. http://dx.doi.org/10.1016/S0021-9797(03)00607-6

[41] Suciu, N.A. and Capri, E. (2009) Adsorption of Chlorpyrifos, Penconazole and Metalaxyl from Aqueous Solution by Modified Clays. Journal of Environmental Science and Health Part B, 44, 525-532. http://dx.doi.org/10.1080/03601230902997543

[42] Nir, S., Undabeytia, T., Yaron, D., El-Nahhal, Y., Polubesova, T., Serban, S., Rytwo, G., Lagaly, G. and Rubin B. (2000) Optimization of Adsorption of Hydrophobic Herbicides on Montmorillonite Preadsorbed by Monovalent Organic Cations: Interaction between Phenyl rings. Environmental Science and Technology, 34, 1269-1274. 
http://dx.doi.org/10.1021/es9903781

[43] Baglieri, A., Nègre, M., Trotta, F., Bracco, P. and Gennari, M. (2013) Organo-Clays and Nanosponges for Acquifer Bioremediation: Adsorption and Degradation of Triclopyr. Journal of Environmental Science and Health Part B, 48, 784-792. http://dx.doi.org/10.1080/03601234.2013.780943

[44] Rubin, B., El-Nahhal, Y., Nir, S. and Margulies, L. (2000) Slow Release Formulations of Pesticides. US Patent No. 6,261,997.

[45] MacEwan, C. and Wilson, J. (1980) Interlayer and Intercalation Complexes of Clay Minerals. In: Brindley, G.W. and Brown, G., Eds., Crystal Structures of Clay Minerals and Their X-Ray Identification, Mineralogical Society, London, 197-248.

[46] Stevens, J.J. and Anderson, S.J. (1996) Orientation of Trimethylphenylammonium (TMPA) on Wyoming Montmorillonite: Implications for Arene Sorption. Clays and Clay Minerals, 44, 132-141. http://dx.doi.org/10.1346/CCMN.1996.0440112

[47] Olivella, M.A., Bassicaupi, C., Bianchi, A., Fiol, N. and Villaescusa, I. (2015) New Insights into the Interactions between Cork Chemical Components and Pesticides. The Contribution of $\pi-\pi$ Interactions, Hydrogen Bonding and Hydrophobic Effects. Chemosphere, 119, 863-870. http://dx.doi.org/10.1016/j.chemosphere.2014.08.051

[48] Jaynes, W.F. and Boyd, S.A. (1991) Clay Mineral Type and Organic Compound Sorption by hexadecyltrimethylammoium-Exchanged Clays. Soil Science Society of America Journal, 55, 43-48. http://dx.doi.org/10.2136/sssaj1991.03615995005500010007x

[49] El-Nahhal, Y. and Safi, J. (2005) Adsorption of Benzene and Naphthalene to Modified Montmorillonite. Journal of Food, Agriculture and Environment, 3, 295-298.

[50] El-Nahhal, Y., Nir, S., Serban, C., Rabinovitch, O. and Rubin, B. (2000) Montmorillonite-Phenyltrimethylammonium Yields Environmentally Improved Formulations of $\mathrm{Hy}-$ drophobic Herbicides. Journal of Agricultural and Food Chemistry, 48, 4791-4801. http://dx.doi.org/10.1021/jf000327j

[51] Armenta, S., Quintas, G., Grrigues, S. and de la Guadia, M. (2005) A Validated and Fast Procedure for FTIR Determination of Cypermetherin and Chlorpyrifos. Talanta, 67, 634639. http://dx.doi.org/10.1016/j.talanta.2005.03.008

[52] Schmidt, P., Dybal, J. and Trchova, M. (2006) Investigations of the Hydrophobic and Hydrophilic Interactions in Polymer-Water Systems by ATR FTIR and Raman Spectroscopy. Vibrational Spectroscopy, 42, 278-283. http://dx.doi.org/10.1016/j.vibspec.2006.05.005

[53] Shah, R.M., Alam, M., Ahmad, D., Waqas, M., Ali, Q., Binyamin, M. and Shad S.A. (2016) Toxicity of 25 Synthetic Insecticides to the Field Population of Culex quinquefasciatus Say. Parasitology Research, 1-7. http://dx.doi.org/10.1007/s00436-016-5218-8 
Submit or recommend next manuscript to SCIRP and we will provide best service for you:

Accepting pre-submission inquiries through Email, Facebook, LinkedIn, Twitter, etc. A wide selection of journals (inclusive of 9 subjects, more than 200 journals)

Providing 24-hour high-quality service

User-friendly online submission system

Fair and swift peer-review system

Efficient typesetting and proofreading procedure

Display of the result of downloads and visits, as well as the number of cited articles

Maximum dissemination of your research work

Submit your manuscript at: http://papersubmission.scirp.org/

Orcontact jeas@scirp.org 